\title{
A multicompartmental model to describe marker excretion patterns in ruminant faeces
}

\author{
By M. S. DHANOA, R. C. SIDDONS, J. FRANCE AND D. L. GALE \\ The Grassland Research Institute, Hurley, Maidenhead, Berkshire SL6 5LR
}

(Received 18 May 1984 - Accepted 31 December 1984)

\begin{abstract}
1. A multicompartmental model, which assumes first-order kinetics, is proposed to describe digesta flow along the gastrointestinal tract of ruminants.

2. Solution of the model yields a multiplicative equation, containing a single-exponential term and a double-exponential term, for describing faecal outflow rate.

3. The logarithmic transformation of the equation was fitted to eighty-two excretion curves obtained after the administration of marker into the rumen of cattle and sheep, and compared with other published models.

4. It was found to be superior to the other models in that it fitted all the data sets successfully.
\end{abstract}

The extent to which dietary components are fermented in the rumen is a function of both rate of fermentation and residence time in the rumen. The latter, usually expressed as the mean retention time (i.e. the reciprocal of the fractional outflow rate; MRT), can be determined from the decrease in the concentration of a non-absorbable marker in rumen digesta after an intraruminal dose of marker. This technique, whilst generally satisfactory for solute markers, is less reliable for particulate markers because of difficulties in obtaining representative samples of rumen digesta. The faecal marker excretion technique (Grovum \& Williams, 1973) overcomes the problem of representative sampling and also has the added advantage that fistulated animals are not necessarily required. It is based on the fact that the pattern of marker excretion in the faeces after an intraruminal dose of marker reflects the cumulative effects of marker residence time in the various sections of the digestive tract. Provided a satisfactory mathematical description of the excretion curve can be achieved and the component parts identified, or at least that part relating to the rumen, the MRT in the rumen can be obtained. Blaxter et al. (1956) suggested that the ruminant gut is essentially composed of two mixing compartments and a tubular compartment, and that digesta flow can be described by a model consisting of two exponential terms and a time delay. Subsequently, Grovum \& Williams (1973) used this model to describe the change in marker concentration in sheep faeces following an intraruminal dose of marker and showed that the longer MRT was associated with the rumen. However, other workers (e.g. Milne et al. 1978; Ellis et al. 1979; Udén et al. 1982) have encountered difficulties in fitting this model to faecal marker excretion curves. We also found that the Blaxter et al. (1956) model did not always satisfactorily describe the pattern of marker excretion in ruminant faeces.

In their paper on the theoretical considerations and computer simulation of digesta passage, Grovum \& Phillips (1973) concluded that 'a poor fit between the observed concentration of marker and the predicted values for the two-pool model may indicate that a model with two compartments is not descriptive of passage of marker through the gut. Thus new models and new equations can be sought that are more appropriate.' In the present paper an alternative model to describe faecal marker excretion is proposed and was derived by considering digesta flow as a multicompartmental exponential process. It consists of a multiplicative equation containing an exponential term and a doubleexponential term:

$$
y=A \mathrm{e}^{-c_{1} t} \exp \left[-B \mathrm{e}^{-c_{2} t}\right],
$$




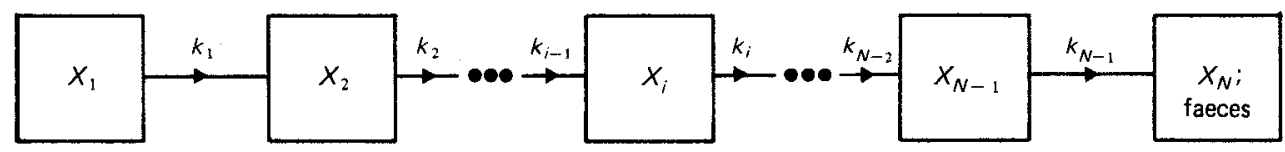

Fig. 1. The multicompartmental model.

where $y$ denotes faecal marker outflow, $t$ is time and $A, B, c_{1}$ and $c_{2}$ are parameters. The model on the logarithmic scale was found to fit a wide range of faecal-marker-excretion data successfully.

\section{MODEL DERIVATION}

Consider the multicompartmental ( $N$-compartmental) model of digesta flow shown schematically in Fig. 1. In the model, the state variables $X_{1}, X_{2}, \ldots, X_{N}$ represent the amounts of a unit of marker in the compartments concerned at time $t(\mathrm{~h})$. No attempt is made at this stage to nominate any compartment other than the final one, which is faeces. When $t=0$ then $X_{1}=1$ and $X_{2}=X_{3}=\ldots=X_{N}=0$ as all the marker is present in the first compartment initially; as $t \rightarrow \infty$ then $X_{1}, X_{2}, \ldots, X_{N-1} \rightarrow 0$ and $X_{N} \rightarrow 1 . k_{1}, k_{2}, \ldots, k_{N-1}$ (/h) are rate constants. Assuming linear kinetics, the dynamics of the system are described by $N$ linear first-order differential equations:

$$
\begin{gathered}
\frac{\mathrm{d} X_{1}}{\mathrm{~d} t}=-k_{1} X_{1}, \\
\frac{\mathrm{d} X_{2}}{\mathrm{~d} t}=k_{1} X_{1}-k_{2} X_{2}, \\
\vdots \\
\frac{\mathrm{d} X_{i}}{\mathrm{~d} t}=k_{i-1} X_{i-1}-k_{i} X_{i}, \\
\vdots \\
\frac{\mathrm{d} X_{N-1}}{\mathrm{~d} t}=k_{N-2} X_{N-2}-k_{N-1} X_{N-1}, \\
\frac{\mathrm{d} X_{N}}{\mathrm{~d} t}=k_{N-1} X_{N-1} .
\end{gathered}
$$

An analytic solution to eqns (2.1-2.5) for $k_{1} \neq k_{2} \neq \ldots \neq k_{N-1}$ employing advanced linear algebra is given by Jacques (1972). A much simpler solution, obtained by mathematical induction, is derived by France et al. (1985), and the faecal outflow rate, $\mathrm{d} X_{N} / \mathrm{d} t$, is given by

$$
\frac{\mathrm{d} X_{N}}{\mathrm{~d} t}=\left\{\prod_{i=1}^{N-1} k_{i}\right\} \times\left\{\sum_{i=1}^{N-1}\left[\mathrm{e}^{-k_{i} t} \prod_{\substack{j=1 \\ J \neq i}}^{N-1}\left(k_{j}-k_{i}\right)\right]\right\} .
$$

Certain simplifying assumptions are now introduced to the $\mathrm{N}$-compartmental model in order to reduce the number of parameters (rate constants). First, it is noted that eqn (3) is symmetrical in the $k_{i}$ and therefore, for the overall behaviour of the system, the rate constants can be ordered so that $k_{1}<k_{2}<\ldots<k_{N-1}$, without loss of generality. To derive a relation between the rate constants, it is assumed that

$$
k_{i+1}=k_{i}+\Delta, \quad i \geqslant 2,
$$

where $\Delta$ is a small positive constant. The equation

$$
k_{i}=k_{2}+(i-2)\left(k_{2}-k_{1}\right), \quad \text { for } i=3,4, \ldots, N-1 \text {, }
$$


is equivalent to eqn (4) with $\Delta=k_{2}-k_{1}$. Using eqn (5) to substitute for $k_{i}(i \geqslant 3)$ and making use of the series expansion of $(1+x)^{n}$, where $n$ is a positive integer, after some algebraic manipulation eqn (3) yields:

$$
\frac{\mathrm{d} X_{N}}{\mathrm{~d} t}=A \mathrm{e}^{-k_{1} t}\left[1-\mathrm{e}^{-\left(k_{2}-k_{1}\right) t}\right]^{N-2},
$$

where

$$
A=k_{1} k_{2}\left\{\prod_{i=3}^{N-1}\left[k_{2}+(i-2)\left(k_{2}-k_{1}\right)\right]\right\} /\left[(N-2) !\left(k_{2}-k_{1}\right)^{N-2}\right] .
$$

Using the approximation

$$
\left[1-\mathrm{e}^{-\left(k_{2}-k_{1}\right) t}\right]^{N-2} \approx \exp \left[-(N-2) \mathrm{e}^{-\left(k_{2}-k_{1}\right) t}\right]
$$

which is valid for large $N$, eqn (6) then becomes

$$
\frac{\mathrm{d} X_{N}}{\mathrm{~d} t}=A \mathrm{e}^{-k_{1} t} \exp \left[-(N-2) \mathrm{e}^{-\left(k_{2}-k_{1}\right) t}\right] .
$$

The expressions for the faecal outflow rate given by eqns (6) and (8) have just three independent, non-linear parameters, $k_{1}, k_{2}$ and $N$, where $k_{1}, k_{2}$ are rate-constants and $N$ the number of compartments in the model. $A$ is a scale parameter dependent on $k_{1}, k_{2}$ and $N$. $k_{1}$ and $k_{2}$ represent the two compartments of the gastrointestinal tract having the longest retention times, and therefore most probably the rumen and the caecum. If the pattern of marker excretion is found to be influenced by feeding frequency or some other factor(s) (e.g. as evidenced by a cyclic effect in the distribution of the residuals) then it should be possible to take this into account by incorporating an additional function(s) in eqn (8).

\section{MATERIALS AND METHODS}

Marker preparation

CrEDTA was prepared as described by Binnerts et al. (1968). CoEDTA and Cr mordants of feedstuffs were prepared as described by Udén et al. (1980). Ytterbium-labelled feed was prepared by soaking the feed in ytterbium acetate solution for $24 \mathrm{~h}$ and then washed with water to remove unbound $\mathrm{Yb}$.

\section{Experimental procedures}

A total of eighty-two individual marker excretion curves were obtained in four separate studies; two with sheep and two with cattle. In study 1, CrEDTA and the Cr mordants of granulated soya-bean meal, groundnut meal and fishmeal were administered into the rumen of sheep (live weight approximately $65 \mathrm{~kg}$ ) given continuously a diet of chopped grass hay (800 g dry matter (DM)/d); in study 2, CoEDTA, Cr-mordanted chopped dried grass (particle length $25-50 \mathrm{~mm}$ ) and $\mathrm{Yb}$-labelled chopped dried grass (particle length $25-50 \mathrm{~mm}$ ) were administered into the rumen of sheep (live weight approximately $60 \mathrm{~kg}$ ) given continuously a diet of chopped dried grass $(1 \mathrm{~kg} \mathrm{DM} / \mathrm{d})$; in study $3, \mathrm{Cr}$-mordanted precision-chopped silage (particle length $25-50 \mathrm{~mm}$ ) was administered into the rumen of cattle (live weight approximately $150 \mathrm{~kg}$ ) given twice daily a diet of grass silage plus concentrates $(3.45 \mathrm{~kg} \mathrm{DM} / \mathrm{d})$; in study 4 , chromic oxide-impregnated paper was administered by mouth to cattle (live weight approximately $300 \mathrm{~kg}$ ) given ad lib. a diet of grass silage or grass hay. In all studies faeces were collected at approximately six hourly intervals for $6 \mathrm{~d}$ (sheep) or $8 \mathrm{~d}$ (cattle) after marker administration. Faecal samples were dried at $100^{\circ}$ for $24 \mathrm{~h}$ and ground. 


\section{Analytical methods}

The concentrations of $\mathrm{Cr}, \mathrm{Co}$ and $\mathrm{Yb}$ in faeces were measured by atomic absorption spectrometry. For this purpose the faeces were ashed at $500^{\circ}$ overnight and $\mathrm{Cr}$ extracted by wet digestion as described by Christian \& Coup (1954) whilst Co and Yb were extracted by shaking for $2 \mathrm{~h}$ with a mixture $(1: 1, \mathrm{v} / \mathrm{v})$ of $2 \cdot 25 \mathrm{M}$-sulphuric acid and $2 \cdot 25 \mathrm{M}$-hydrochloric acid containing $1000 \mu \mathrm{g} \mathrm{K}$ as potassium chloride/l.

\section{Computer curve-fitting}

All curve fitting was done on a main-frame computer (DEC VAX/750) using a maximum likelihood program MLP (Ross, 1980) which allows direct iterative estimation of non-linear parameters using efficient algorithms such as Newton's method. In situations where no solution can be found, MLP has facilities to study the behaviour of the function with respect to one or more parameters in deciding whether the model is inappropriate or the data is inadequate. The simplified form of the model of Blaxter et al. (1956) relating change in faecal marker concentration $(y)$ with time $(t)$ :

$$
\begin{gathered}
y=S \mathrm{e}^{-k_{1} t}-R \mathrm{e}^{-k_{2} t}, \\
S=k_{1} k_{2} \mathrm{e}^{k_{1} \tau} /\left(k_{2}-k_{1}\right), \\
R=k_{1} k_{2} \mathrm{e}^{k_{2} \tau} /\left(k_{2}-k_{1}\right),
\end{gathered}
$$

where $\tau$ denotes lag or transit time and $k_{1}, k_{2}$ are rate constants, was found to be computationally more efficient than the form given by Grovum \& Williams (1973). For fitting the Blaxter et al. (1956) model and also eqns (6) and (8), good initial estimates of parameters and their ranges were specified and up to fifty iterations allowed whereas using eqn (10) (p. 667), it was often not necessary to specify initial estimates and ranges. The initial parameter values were obtained by computer fitting of the graphical method described by Grovum \& Williams (1973). The effect of step length on the computer fitting of the Blaxter et al. (1956) model was examined using steps of either 0.01 or 0.1 and 0.01 of the initial parameter values. Step lengths of 0.1 of the initial parameter estimates were found to be the most successful in terms of convergence to a solution, and were used in the standard fitting procedure adopted. The success of any fit was judged on the basis of three criteria: (1) ability to describe the data without systematically overestimating or underestimating any section of the curve, (2) biologically acceptable parameter estimates, and (3) convergence to a solution, preferably for different sets of initial parameter values because in non-linear least squares too many iterations for convergence or non-convergence and an unrepeatable solution for different starting values can be symptomatic of an inappropriate model.

\section{RESULTS AND DISCUSSION}

In both sheep and cattle, the pattern of marker excretion in the faeces was generally similar to that described by Grovum \& Williams (1973). Following the introduction of marker into the rumen, there was a delay before it appeared in the faeces after which the concentration increased with time and subsequently decreased. However, in many cases the initial rate of increase in marker concentration was slower than expected on the basis of marker flow through the tract being represented by the two-compartment exponential model of Blaxter et al. (1956) and, when plotted on a semi-logarithmic scale, the curves tended to resolve into a straight line and an exponential-type component rather than two straight lines. Furthermore, using computer-fitting, the Blaxter et al. (1956) model fitted only thirty-three 
of a total of eighty-two individual marker excretion curves. In all other cases, sensible estimates of parameters were not obtained due to either the non-convergence of the non-linear iterative procedure or to a systematic underestimation or overestimation of sections of the curve, indicating that the model did not satisfactorily describe the data. Increasing the number of compartments in the model to three, as used by Milne et al. (1978) to describe the pattern of ruthenium excretion in the faeces of heather (Calluna vulgaris)-fed sheep, also proved to be of little benefit. Increasing the number of compartments in a sequential exponential model (thus increasing the number of rate constants) above two, makes the model difficult to fit and, if fit is possible, the rate constants for the additional compartments tend to be high. Furthermore the inclusion of more and more exponential terms reduces their theoretical significance (Defares \& Sneddon, 1961).

The slow initial increase in faecal marker concentration found in the present study was also found in the study of Ellis et al. (1979) and they suggested that it could be accommodated by the inclusion of a gamma time dependency of two in the faster rate constant of the Blaxter et al. (1956) model. Whilst this 'time-dependent, time-independent' model appeared to be superior to the original Blaxter et al. (1956) model, in that it could be fitted to forty-four of the eighty-two excretion curves, it was very sensitive to initial data points and in many cases there was poor agreement between the predicted and observed concentrations in the ascending phase of the curve. It was therefore likely to yield biased estimates of the larger rate constant. The introduction of a time dependency of two into the Blaxter et al. (1956) model is in essence representing the gastrointestinal tract by three pools and a delay with two contiguous pools having the same rate constant (France et al. 1985).

Since none of the previously mentioned models proved satisfactory for describing the pattern of marker excretion in ruminant faeces, a new model was developed based on the assumption that the ruminant digestive tract can be represented by an unspecified number of exponential compartments with the pattern of marker excretion being largely defined by events occurring in the two compartments having the smallest rate constants $\left(k_{1}\right.$ and $\left.k_{2}\right)$. In order to achieve non-linear parameter reduction and so facilitate parameter estimation the assumption was made that the rate constants of all other pools increased by a small constant amount (i.e. $k_{2}-k_{1}$ ) (eqns (4) and (5)). Digesta flows from the rumen, abomasum and caecum are likely to be exponential processes whilst events occurring within the rumen (e.g. marker mixing and particle reduction) may also be envisaged as exponential-type processes. The flow of digesta along the tubular section of the gut (i.e. the small and large intestine) is probably best described by longitudinal diffusion but can be approximated by a series of exponential components.

The multicompartmental model in the form of eqn (6) did not fit all the sets of data because when peak marker concentration occurred relatively late, parameter $N$ became large causing the estimation procedure to break down as it was not possible to calculate sums-of-squares functions owing to exponential overflow (exponent $>98$ ). Logarithmic transformation of eqn (6) was considered but found to be very sensitive to initial parameter values and step-lengths during the iterative process because $1-\mathrm{e}^{-\left(k_{2}-k_{1}\right) t}$ is less than unity and therefore, when taking natural logarithms, small changes in the $k$ values will result in large changes in the function value and thus prevent convergence to a solution. This problem was overcome by deriving the double-exponential form of the model (eqn (8)) which was further simplified by logarithmic transformation to yield:

$$
\ln \left(\mathrm{d} X_{N} / \mathrm{d} t\right)=\ln A-k_{1} t-(N-2) \mathrm{e}^{-\left(k_{2}-k_{1}\right) t} .
$$

In this form the model effectively has only one non-linear parameter (i.e. $k_{2}-k_{1}$ ) which can be estimated very efficiently using non-linear least squares. Consequently, computation time 


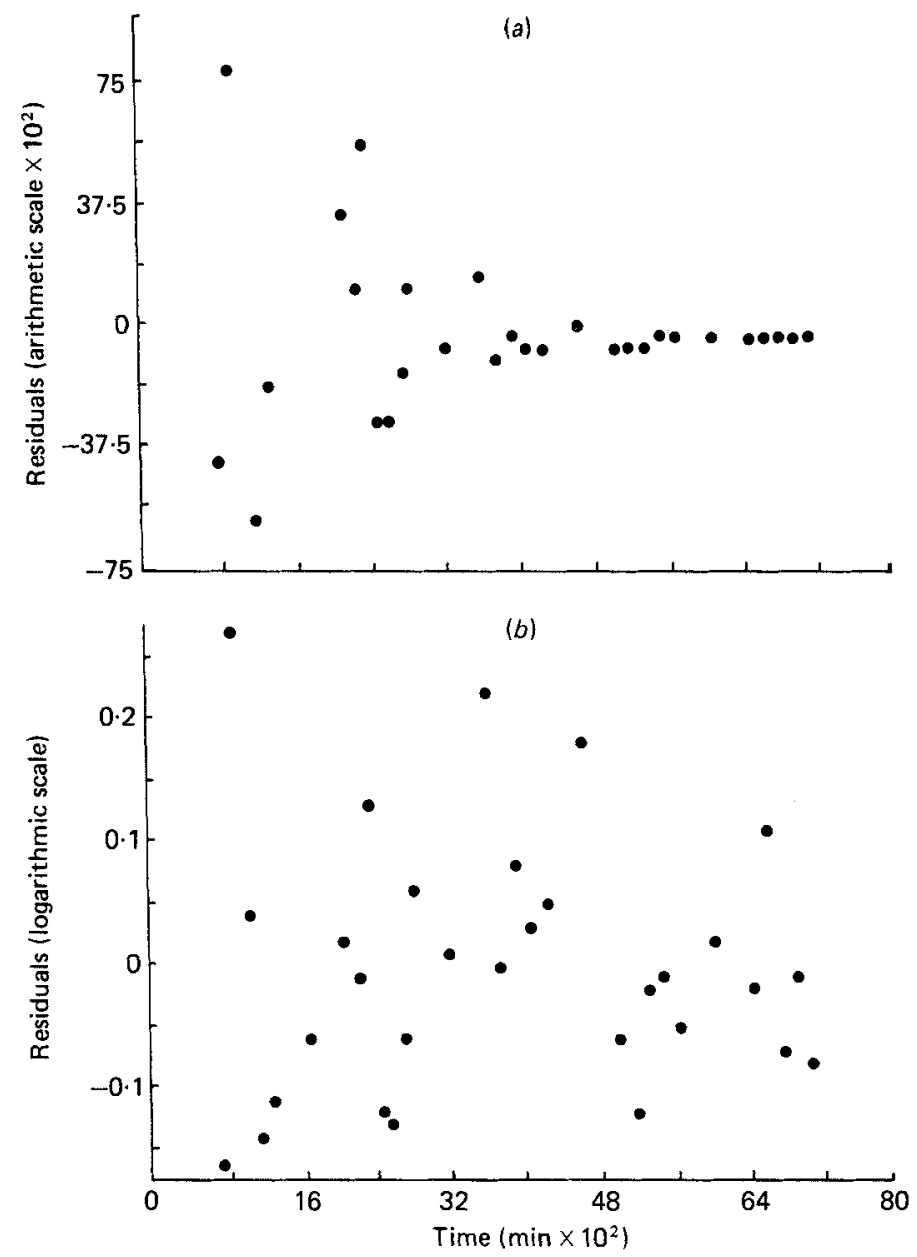

Fig. 2. The distribution of residuals when the faecal chromium excretion data of Grovum \& Williams (1973) was analysed using (a) the Blaxter et al. (1956) model and (b) the multicompartmental model (eqn (10), p. 667).

was reduced to less than one-third compared with the non-linear form (eqn (8)) or the time-dependent, time-independent model of Ellis et al. (1979). Logarithmic transformation also has the additional advantage that it stabilizes the variance and therefore satisfies much more closely the implicit assumption of constant variance of the response variable. A reason for this is that marker excretion data must always be positive and their respective fitted values close to zero can only have their errors added, otherwise values obtained may become negative which is inadmissible. In such situations variation is expected to be non-constant and logarithmic transformation is usually used as a normalizing and variance-stabilizing device (Waldo et al. 1971; Ross, 1981). The distribution of the residuals when the $\mathrm{Cr}$ excretion data of Grovum \& Williams (1973) were fitted by computer to either the log form of the proposed model or the Blaxter et al. (1956) model, is shown in Fig. 2. The variance-stabilizing effect of logarithmic transformation is demonstrated by the uniform distribution of residuals whereas with the Blaxter et al. (1956) model the distribution was non-uniform. A similar non-uniform distribution was obtained when data were fitted to eqns (6) and (8). In all three cases (i.e. the Blaxter et al. (1956) model and eqns (6) and (8)), 
Table 1. Estimates of rate constants $\mathrm{k}_{1}$ and $\mathrm{k}_{2}$

(Mean values with their standard errors)

\begin{tabular}{|c|c|c|c|c|c|c|c|c|}
\hline \multirow[b]{2}{*}{ Study } & \multirow[b]{2}{*}{ Animal } & \multirow[b]{2}{*}{ Diet } & \multirow[b]{2}{*}{ Marker } & \multirow[b]{2}{*}{$n$} & \multicolumn{2}{|c|}{$k_{1}$} & \multicolumn{2}{|c|}{$k_{2}$} \\
\hline & & & & & Mean & $\mathrm{SE}$ & Mean & $\mathrm{SE}$ \\
\hline 1 & $\mathbf{S}$ & Hay & CrEDTA & 4 & 0.0408 & 0.0036 & $0 \cdot 1280$ & 0.0140 \\
\hline 1 & $\mathrm{~s}$ & Hay & Cr-mordant & 12 & 0.0323 & 0.0021 & $0 \cdot 1190$ & 0.0074 \\
\hline 2 & S & Dried grass & CoEDTA & 6 & 0.0500 & 0.0089 & 0.2187 & 0.0367 \\
\hline 2 & $\mathrm{~S}$ & Dried grass & $\begin{array}{l}\text { Ytterbium- } \\
\text { feed }\end{array}$ & 6 & 0.0387 & 0.0057 & $0 \cdot 1694$ & 0.0116 \\
\hline 2 & S & Dried grass & Cr-mordant & 6 & 0.0266 & 0.0041 & 0.1452 & 0.0247 \\
\hline 3 & $\mathrm{C}$ & Silage & Cr-mordant & 26 & 0.0258 & 0.0008 & 0.1785 & 0.0115 \\
\hline 4 & $\mathrm{C}$ & Silage-hay & $\begin{array}{l}\text { Chromic oxide } \\
\text { paper }\end{array}$ & 24 & 0.0423 & 0.0015 & 0.2015 & 0.0064 \\
\hline
\end{tabular}

$\mathrm{C}$, cattle; S, sheep; $n$ number of curves.

variance could be stabilized through the use of log least squares in which weights are taken to be proportional to $1 / y^{2}$ but this had little or no effect on parameter estimates. For those data sets which could not be described by the Blaxter et al. (1956) model, the use of log least squares procedure did not overcome the problem.

Computer fitting of the proposed model (eqn (10)) and the Blaxter et al. (1956) model to the data of Grovum \& Williams (1973) gave similar values of $k_{1}(0.057 / \mathrm{h}$ and $0.051 / \mathrm{h}$ respectively) and values of $0.275 / \mathrm{h}$ and $0.220 / \mathrm{h}$ respectively for $k_{2}$. Values of $0.057 / \mathrm{h}$ and $0 \cdot 174 / \mathrm{h}$ for $k_{1}$ and $k_{2}$ respectively were obtained by Grovum \& Williams (1973) using their graphical method of fitting the Blaxter et al. (1956) model. For each of the thirty-three data sets in the present study which could be described by both models, the estimates of $k_{1}$ were also very similar (0.034 (SE 0.0018) and 0.031 (SE 0.0016) from the Blaxter et al. (1956) and the new model respectively) whereas $k_{2}$ tended to be higher using the new model ( $0 \cdot 110$ (SE 0.0079 ) and 0.200 (SE 0.0095)). The regression relation between the $k_{2}$ values obtained using the new model $\left(k_{2}^{*}\right)$ and the $k_{2}$ values obtained using the Blaxter et al. (1956) model $\left(k_{2}^{\prime}\right)$ was

$$
\begin{aligned}
& k_{2}^{\prime}=-0.026(\mathrm{SE} 0.0175) \\
& +0.682 k_{2}^{*} \text { (SE 0.0843), (residual SD (RSD) 0.026, } r 0.824 \text { ), } \\
& \text { or } \quad k_{2}^{\prime}=-0.002(\mathrm{SE} 0.0190)+0 \cdot 752 k_{2}^{*}(\mathrm{SE} 0.0836) \\
& -1.219 k_{1}^{*} \text { (SE 0.5030), (RSD 0.024, } R \text { 0.855), }
\end{aligned}
$$

where $k_{1}^{*}$ is the smallest rate constant obtained with the new model.

The proposed model (eqn (10)) provided a satisfactory description of all eighty-two marker excretion curves with variance accounted for ranging between $91-99 \cdot 8 \%$. Typical values of the parameter $N$ ranged between 10 and 60 . The values obtained for $k_{1}$ and $k_{2}$ are presented in Table 1. Assuming that $k_{1}$ represents rumen outflow rate, then the results for the sheep are consistent with expectations in that the outflow rates of the solute markers (CrEDTA and CoEDTA) were higher than those of the particulate-phase markers. The higher outflow rate of the $\mathrm{Yb}$-labelled chopped dried grass compared with the $\mathrm{Cr}$-mordanted chopped dried grass in study 2 might also be expected on the basis that the mordanting procedure renders the feed resistant to microbial degradation. Mean values for $k_{2}$ were 3-5.5 times greater than those for $k_{1}$ in the sheep studies and 4.5-7 times greater in the cattle studies. 
Mathematically, the MRT in the whole digestive tract for the scheme in Fig. 1 is given by

$$
\mathrm{MRT}=\frac{1}{k_{1}}+\frac{1}{k_{2}}+\sum_{i=3}^{N-1} \frac{1}{k_{2}+(i-2)\left(k_{2}-k_{1}\right)}, \quad k_{2}>k_{1} .
$$

The third term in eqn (12) represents the transit time $\tau$. For the thirty-three data sets in the present study which could be described by both the new model and the Blaxter et al. (1956) model, the mean values for MRT were 60 (SE 1.6) and 59 (SE 1.5) h respectively and for $\tau$ were 20 (SE 0.5) and 17 (SE 0.4) h respectively. Faichney \& Boston (1983) found that the Blaxter et al. (1956) model underestimated both the observed MRT and $\tau$.

The time to peak outflow, $t_{p}$, is found by differentiating eqn (10):

$$
t_{p}=\left\{\ln \left[(N-2)\left(k_{2}-k_{1}\right) / k_{1}\right]\right\} /\left(k_{2}-k_{1}\right) .
$$

Values of $t_{p}$ were found to be practically the same whether obtained using the new model or the Blaxter $e t$ al. (1956) model. As $t$ becomes large, eqn (10) tends to the straight line In $A-k_{1} t$ and thus, knowing the minimum (min) level of detectable outflow $\left(\mathrm{d} X_{N} / \mathrm{d} t\right)_{\min }$, it is possible to estimate time for complete removal, $t_{c}$, from

$$
t_{c} \approx\left[\ln A-\ln \left(\mathrm{d} X_{N} / \mathrm{d} t\right)_{\min }\right] / k_{1} .
$$

The allocation of the rate constants to specific compartments in the digestive tract is not totally clear. Originally Blaxter et al. (1956) suggested that the slower rate constant represented events occurring post-ruminally and that the faster rate constant represented events occurring in the rumen. However, Grovum \& Williams (1973) showed that the slower rate constant related to rumen outflow and suggested that the faster rate constant probably represented events occurring post-ruminally. The slower rate constant, therefore, has generally been assumed to represent rumen outflow and in some cases has been determined by analysis of the post-peak part of the excretion curve as a single exponential. In our experience this proved unsatisfactory because the value for the rate constant so obtained varied depending on the time taken post-peak as the starting point of the curve. Furthermore, the determination of only the smallest of the outflow rate constants in this manner and the assumption that it represents rumen outflow may be incorrect because Faichney \& Boston (1983) found that in some circumstances outflow from the caecum can be slower than from the rumen. They suggested, on the basis that the liquid and particulate phases do not generally behave independently in the caecum, that the allocation of the rate constants to the respective compartments can be achieved provided the two outflow rate constants are obtained for both a solute marker and a particulate marker. The new model does fulfil the requirement of providing two rate constants, which in theory relate to the two compartments having the longest MRT, although it has yet to be demonstrated clearly that they can be identified as the rumen and the caecum. The results obtained in study 1 (Table 1) for CrEDTA and the Cr-mordants are consistent with $k_{2}$ representing caecal outflow rate and $k_{1}$ representing rumen outflow rate whereas the results obtained in study 2 do not allow a similar conclusion to be drawn.

The authors thank R. D. Baker and Dr M. Gill for use of their data, and Dr J. H. M. Thornley for advice and encouragement. The Grassland Research Institute is financed through the Agricultural and Food Research Council; the work is in part commissioned by the Ministry of Agriculture, Fisheries and Food. 


\section{REFERENCES}

Binnerts, W. T., Van't Klooster, A. Th. \& Frens, A. M. (1968). Veterinary Record 82, 470.

Blaxter, K. L., Graham, N. McC. \& Wainman, F. W. (1956). British Journal of Nutrition 10, 69-91.

Christian, K. R. \& Coup, M. R. (1954). New Zealand Journal of Science and Technology A 36, 328-330.

Defares, A. G. \& Sneddon, I. N. (1961). An Introduction to the Mathematics of Medicine and Biology, pp. 582-586. Amsterdam: North-Holland Publishing Company.

Ellis, W. C., Matis, J. H. \& Lascano, C. (1979). Federation Proceedings 38, 2702-2706.

Faichney, G. J. \& Boston, R. C. (1983). Journal of Agricultural Science, Cambridge 101, 575-581.

France, J., Thornley, J. H. M., Dhanoa, M. S. \& Siddons, R. C. (1985). Journal of Theoretical Biology (In the Press.)

Grovum, W. L. \& Phillips, G. D. (1973). British Journal of Nutrition 30, 377-391.

Grovum, W. L. \& Williams, V. J. (1973). British Journal of Nutrition 30, 313-329.

Jacques, J. A. (1972). Compartmental Analysis in Biology and Medicine. Amsterdam: Elsevier.

Milne, J. A., MacRae, J. C., Spence, A. M. \& Wilson, S. (1978). British Journal of Nutrition 40, 347-357.

Ross, G. J. S. (1980). MLP: Maximum Likelihood Program. Harpenden, Herts: Rothamsted Experimental Station.

Ross, G. J. S. (1981). In Mathematics and Plant Physiology, pp. 269-282. [D. A. Rose and D. A. Charles-Edwards, editors]. London: Academic Press.

Udén, P., Colucci, P. E. \& Van Soest, P. J. (1980). Journal of the Science of Food and Agriculture 31, 625-632.

Udén, P., Rounsaville, T. R., Wiggans, G. R. \& Van Soest, P. J. (1982). British Journal of Nutrition 48, $329-339$.

Waldo, D. R., Smith, L. W., Cox, E. L., Weinland, B. T. \& Lucas, H. L. (1971). Journal of Dairy Science 54, 1465-1469. 